\begin{tabular}{|c|c|c|}
\hline $\begin{array}{c}\text { ISSN 2525-4812 (versão online) } \\
\text { ISSN 2238-7641 (versão impressa) } \\
\text { http://www.revistaterceiramargem.com/ } \\
\text { index.php/terceiramargem/index }\end{array}$ & $\begin{array}{c}\text { Recebido em: 3/10/2019 } \\
\text { Aprovado em: 14/1/ } 2020 \\
\text { Período de publicação: jan., } 2021\end{array}$ & $\begin{array}{c}\text { Revista Terceira } \\
\text { Margem Amazônia } \\
(\text { v. } 6 \cdot \text { n. especial } 16 \cdot \text { Jan. } 2021)\end{array}$ \\
\hline
\end{tabular}

Como citar o artigo:

GOMES, M. A. F.; PEREIRA, L. C.; TÔSTO, S. G.; FIGUEIREDO, R. O.; GALDINO, S.; QUARTAROLI, C. F. Perdas de água e de sedimentos em uma sub-bacia como contribuição à analise de serviços ambientais, Extrema, MG. Revista Terceira Margem Amazônia. v. 6, n. especial 16, p. 127-137, 2021. DOI: http://dx.doi.org/10.36882/2525-4812.2021v6i16.ed.esp.p127-137

\title{
PERDAS DE ÁGUA E DE SEDIMENTOS EM UMA SUB-BACIA COMO CONTRIBUIÇÃO À ANÁLISE DE SERVIÇOS AMBIENTAIS, EXTREMA, MG
}

\author{
Marco Antonio Ferreira Gomes ${ }^{1}$ \\ Lauro Charlet Pereira ${ }^{2}$ \\ Sérgio Gomes Tôsto \\ Ricardo de Oliveira Figueiredo ${ }^{4}$ \\ Sérgio Galdino \\ Carlos Fernando Quartaroli ${ }^{6}$
}

Resumo: A sub-bacia do Ribeirão das Posses, localizada no município de Extrema, MG, constitui exemplo de grande importância ambiental não só por estar inserida nos altiplanos da Serra da Mantiqueira, em local de grande fragilidade, mas também, e principalmente, por fazer parte do conjunto de nascentes que compõe os principais cursos d'água que abastecem o Sistema Cantareira, como também parte da Bacia do PCJ. O presente trabalho foi realizado na margem esquerda do Ribeirão das Posses, próximo à nascente principal, a partir de uma topossequência que contemplou dois tipos de cobertura vegetal (mata nativa e pastagem), em diferentes tipos de solo destacando-se os Cambissolos Húmicos, como também Argissolos Câmbicos e Neossolos Litólicos, de acordo com Santos et al. (2018). Nessa topossequência, com declividade variável entre $19 \%$ e $55 \%$, a cobertura de mata corresponde a $10 \%$ da área e o restante $(90 \%)$, a pastagem. A partir da topossequência descrita foram avaliadas perdas de água e de solo (sedimentos) no

\footnotetext{
1 Geólogo, D. Sc. em Solos e Nutrição de Plantas, pesquisador da Embrapa Meio Ambiente, Jaguariúna, SP. E-mail: marco.gomes@embrapa.br (D) https://orcid.org/0000-0002-4405-8736

2 Engenheiro-agrônomo, D. Sc. em Planejamento e Desenvolvimento Rural Sustentável, pesquisador da Embrapa Meio Ambiente, Jaguariúna, SP. E-mail: lauro.pereira@embrapa.br

(D) https://orcid.org/0000-0002-1384-8356

3 Engenheiro-agrônomo, D. Sc. em Desenvolvimento Econômico, pesquisador da Embrapa Territorial, Campinas, SP. E-mail: sergio.tosto@embrapa.br

(D) https://orcid.org/0000-0003-4377-6047

4 Engenheiro-agrônomo, D. Sc. em Biociências e Biotecnologia, Pesquisador da Embrapa Meio Ambiente, Jaguariúna, SP. E-mail: ricardo.figueiredo@embrapa.br

(iD https://orcid.org/0000-0002-0933-4854

5 Engenheiro-agrônomo, D. Sc. em Engenharia Agrícola, pesquisador da Embrapa Territorial, Campinas, SP. E-mail: sergio. galdino@embrapa.br

(iD https://orcid.org/0000-0002-1878-4267

6 Engenheiro-agrônomo, M. Sc. em Agronomia, pesquisador da Embrapa Territorial, Campinas, SP.

E-mail: carlos.quartaroli@embrapa.br

(iD) https://orcid.org/0000-0001-6306-5141
} 
período compreendido entre maio e dezembro de 2016. Essas perdas foram comparadas entre as diferentes coberturas (mata e pastagem), como também entre os diferentes solos na mesma cobertura, como é o caso da pastagem que contempla cinco pontos (parcelas) do total de seis que compõe o esquema amostral adotado.

Em função das perdas de água e de sedimentos avaliadas, o presente trabalho ressalta a importância dos serviços ambientais nesse cenário como mecanismos de ação e de manutenção da propriedade rural com bases sustentáveis.

Palavras-chave: perdas de água, transporte de sedimentos, serviços ambientais, sustentabilidade rural.

\title{
RUNOFF WATER AND SEDIMENTS IN A SUB-BASIN AS A CONTRIBUTION TO THE ANALYSIS OF ENVIRONMENTAL SERVICES, EXTREMA, MG
}

\begin{abstract}
The Ribeirão das Posses sub-basin, located in the municipality of Extrema/MG, is an example of great environmental relevance not only because it is inserted in the highlands of Serra da Mantiqueira in a place of high fragility, but also and, mainly, because it is portion of the set of springs that make up the main rivers that supply the Cantareira System, as well as part of the PCJ Basin. The present work was carried out on the left bank of Ribeirão das Posses, close to the main source, from a topossequence that contemplated two types of vegetation cover (native forest and pasture), in different types of soils, highlighting the Haplumbrepts as well as Ultisols and Leptosols, according Santos et al. (2018). In this topossequence, with a slope varying between 19 and 55\%, the forest cover represents $10 \%$ of the area and the $90 \%$ cover pasture. From the topossequence described, losses of water and soil (sediments) were evaluated between May and December 2016. These losses were compared between coverages forest and pasture, as well as between different soils in the same cover, as is the case of pasture that includes five points of the total of six the make up the adopted sampling scheme. Due to the losses of water and sediments evaluated, the present work emphasizes the relevance of rural properties with sustainable bases.
\end{abstract}

Keywords: Losses water, sediment transport, topossequence of soils, rural sustainability.

\section{Introdução}

Áreas com declividade elevada são naturalmente suscetíveis a processos de movimentação de massa, entre os quais se incluem os processos erosivos. O uso e a cobertura dessas áreas favorecem as perdas de solo por erosão, que é uma das principais responsáveis pela degradação, com redução substancial da produtividade agrícola, danos ao meio ambiente, como também prejuízos em relação às atividades econômicas relacionadas à agricultura. A retirada da vegetação nativa para o uso agrícola sem considerar a capacidade de suporte do solo (FREITAS et al., 2012) resulta na sua imediata exposição e tem como consequência a degradação pela erosão hídrica, ocasionando perdas de partículas, agregados, nutrientes e carbono orgânico (OLIVEIRA et al., 2012), além de reduzir a recarga de água do lençol freático (LIMA et al., 2013b). O controle da erosão hídrica é, de fato, uma das principais medidas para a conservação do solo e da água em uma sub-bacia hidrográfica em sistemas de uso e manejo do solo de forma sustentável (PONTES et al., 2014).

A sub-bacia do Ribeirão das Posses, localizada no município de Extrema, MG, objeto da presente abordagem, constitui exemplo de uso de áreas de elevada declividade como também de grande importância ambiental, principalmente por estar inserida nos altiplanos da Serra da Mantiqueira, local de grande fragilidade, e também por fazer parte do conjunto de nascentes que 
compõe os principais cursos da'água que abastecem o Sistema Cantareira, além de fazer parte da Bacia dos rios Piracicaba, Capivari e Jundiaí (PCJ) (GOMES et al., 2017).

A sub-bacia do Ribeirão das Posses possui 1.196,7 ha e se encontra entre os meridianos de longitude $46^{\circ} 13^{\prime} 14.37^{\prime \prime} \mathrm{O}$ e $46^{\circ} 15^{\prime} 45.07^{\prime \prime} \mathrm{O}$ e entre os paralelos de latitude $22^{\circ} 49^{\prime} 46.71^{\prime \prime} \mathrm{S}$ e $22^{\circ} 53^{\prime} 39.14^{\prime}$ 'S, com altitude que varia de $968 \mathrm{~m}$ a $1.420 \mathrm{~m}$. A precipitação média é em torno de $1.477 \mathrm{~mm} /$ ano (SILVA et al., 2013). Essa sub-bacia está incluída como área piloto no Programa Produtor de Água da Agência Nacional das Águas (ANA), o qual visa recuperar bacias hidrográficas com foco nos recursos hídricos (AGÊNCIA NACIONAL DAS ÁGUAS, 2008; SILVA et al., 2013), sendo a primeira sub-bacia a ter o Projeto Conservador das Águas implantado no município de Extrema, MG, conforme Lei Municipal n² 2.100/05 (BRANCO, 2018).

Por suas características e particularidades, a sub-bacia do Ribeirão das Posses passou a ser pesquisada de forma mais intensiva nos últimos anos por diversas instituições. Isso resultou em um número considerável de informações, entre as quais estão as perdas de água e de sedimentos em uma topossequência constituída por vários tipos de solo próxima à nascente principal, de acordo com Gomes et al. (2017).

Esse estudo de perdas de água e de sedimentos foi realizado no período entre maio e dezembro de 2016. Tais perdas foram comparadas entre as diferentes coberturas vegetais (mata e pastagem), como também entre os diferentes solos com mesma cobertura, como é o caso da pastagem que contempla, pelo menos, três solos distintos em cinco pontos (parcelas) do total de seis que compõem o esquema amostral adotado.

Em razão das perdas de água e de sedimentos avaliadas, o presente trabalho ressalta a importância dos serviços ambientais nesse cenário como mecanismos de ação e de manutenção da propriedade rural com bases sustentáveis.

Os serviços ambientais são comumente entendidos como aqueles que geram benefícios decorrentes da intervenção humana para recuperar um ambiente degradado (MILLENNIUN ECOSYSTEM ASSESMENT, 2005). Trata-se, na prática, de uma intervenção no sentido de recuperar a qualidade do solo, a qualidade e quantidade de água, como também a recomposição da vegetação nativa junto às áreas de drenagem (mata ciliar e nascentes), proporcionando melhorias substanciais para as áreas cultiváveis, como também para as áreas de vegetação natural.

\section{Material e Métodos}

\section{Localização e caracterização da área estudada}

A área estudada localiza-se na margem esquerda da sub-bacia do Ribeirão das Posses, município de Extrema, MG, e encontra-se entre as coordenadas $22^{\circ} 52^{\prime} 50.73$ " e 22 52 ' $53.51^{\prime \prime} \mathrm{S}$ e 46 $15^{\circ} 23.40^{\prime \prime} \mathrm{O}$ e $46^{\circ} 15^{\prime} 32.65^{\prime \prime} \mathrm{O}$ (Figura 1), com seis pontos de amostragem (configuração de uma topossequência), considerando a distribuição dos solos $\mathrm{P} 1(\mathrm{CHe})-22^{\circ} 52^{\prime} 50.73^{\prime \prime} \mathrm{S}$ e

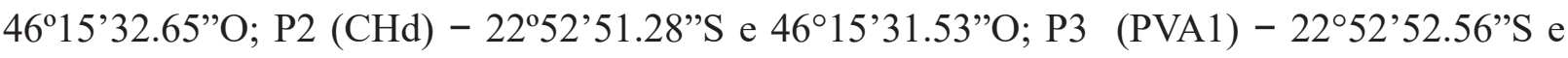

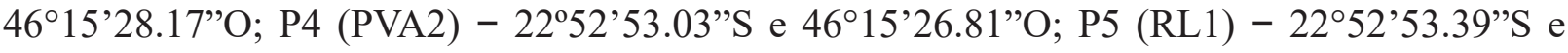

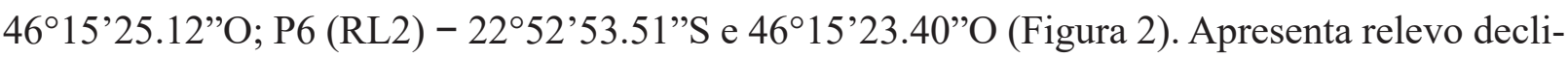


voso e bastante movimentado. O uso do solo predominante é pastagem extensiva com ausência de práticas conservacionistas.

Figura 1. Mapa da localização da área estudada dentro da sub-bacia do Ribeirão das Posses, Extrema, MG.
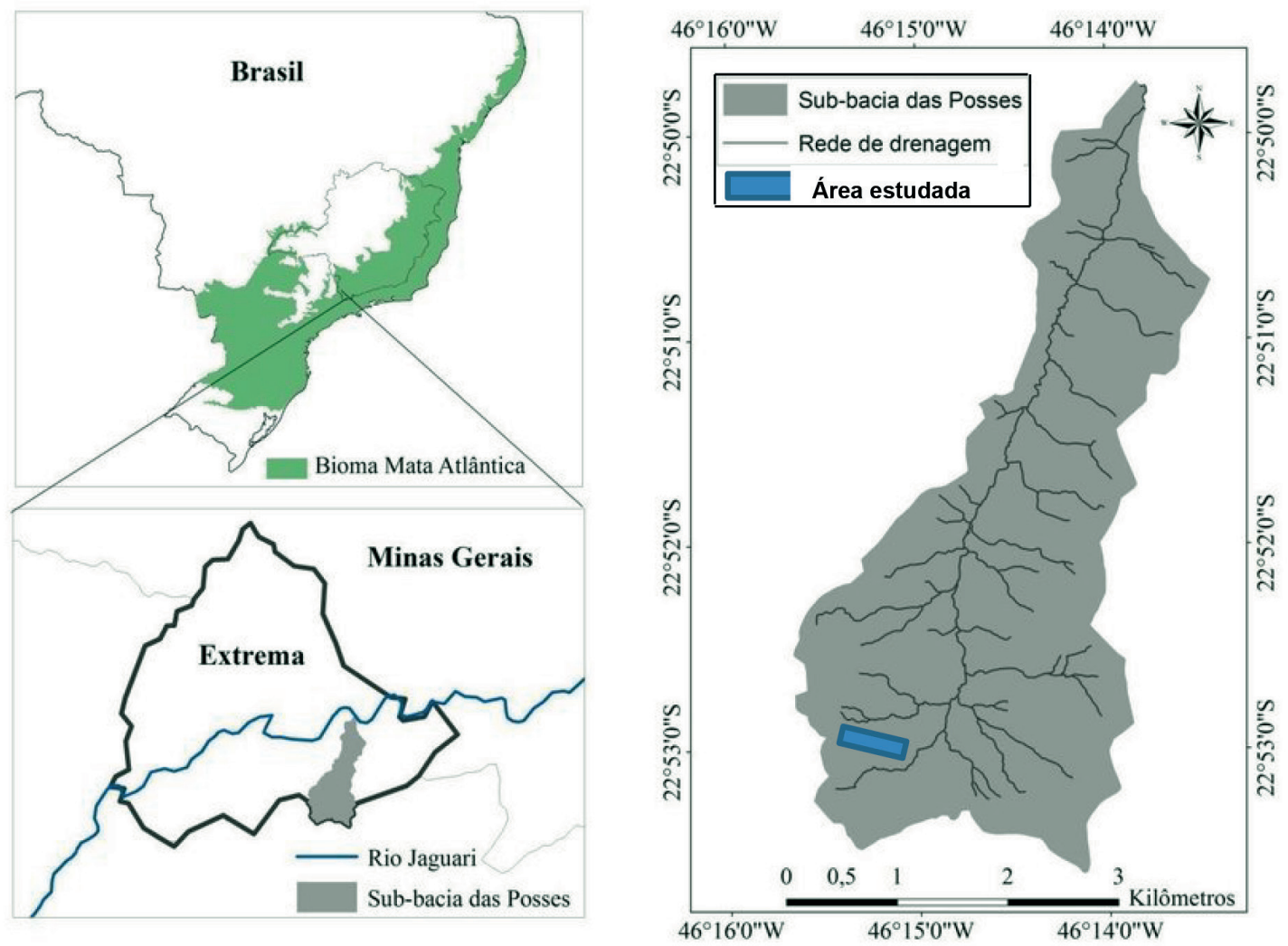

Fonte: Adaptada de Lima et al. (2013a).

A topossequência contemplou dois tipos de cobertura vegetal (mata nativa e pastagem) em diferentes tipos de solo, destacando-se os Cambissolos Húmicos ( $\mathrm{CHe}$ e $\mathrm{CHd}$ ) como também os Argissolos (PVAd) e Neossolos Litólicos (RLd), de acordo como Santos et al. (2018). Nessa topossequência, com declividade variável entre $19 \%$ e 55\%, a cobertura de mata corresponde a $10 \%$ da área e o restante $(90 \%)$, a pastagem.

Figura 2. Localização da área de trabalho com a indicação dos seis pontos estudados.

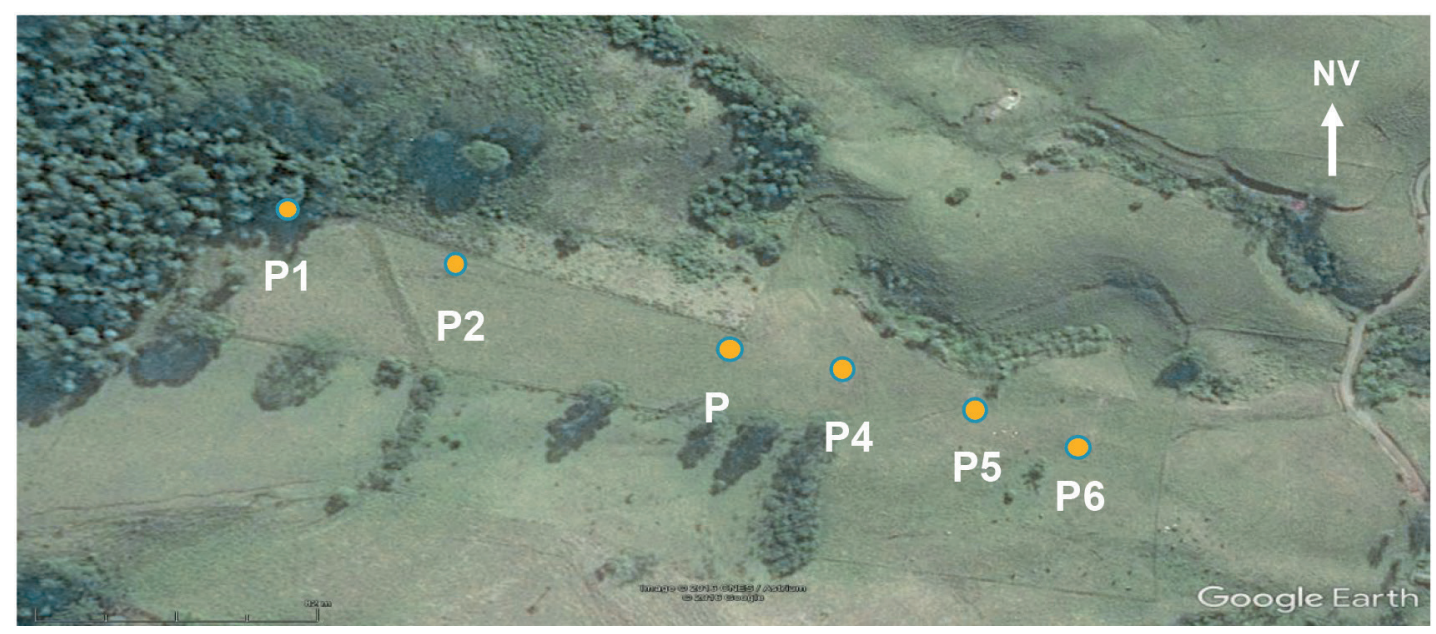

Fonte: Gomes et al. (2017). 


\section{Caracterização dos solos}

Os solos foram classificados de acordo com o levantamento realizado por Da Silva et al. (2013), representados pela classe dos Cambissolos, Argissolos e Neossolos (SANTOS et al., 2018), com detalhamentos de campo realizados por Gomes et al. (2017), de acordo com a descrição da Tabela 1.

Tabela 1. Descrição das características gerais dos solos da topossequência estudada.

\begin{tabular}{|c|c|}
\hline Tipos de solo & Características gerais \\
\hline Cambissolo Húmico Tb Eutrófico (CHe) & $\begin{array}{l}\text { A Húmico, textura argilosa, relevo montanhoso, } \\
\text { substrato granito gnáissico, ocorrência na área de mata, } \\
\text { com declividade de } 55^{\circ} \text {. Coordenadas geográficas: } \\
22^{\circ} 52^{\prime} 50.73^{\prime} \mathrm{S} \text { e } 46^{\circ} 15^{\prime} 32.65^{\prime} \mathrm{O}(\mathrm{P} 1)\end{array}$ \\
\hline Cambissolo Húmico Tb Distrófico (CHd) & $\begin{array}{l}\text { A Húmico, textura argilosa, relevo montanhoso, } \\
\text { substrato granito gnáissico, ocorrência na área de } \\
\text { pastagem, com declividade de } 53 \% \text {. Coordenadas } \\
\text { geográficas: } 22^{\circ} 52^{\prime} 51.28^{\prime} \text { S e } 46^{\circ} 15^{\prime} 31.53^{\prime} \mathrm{O}(\mathrm{P} 2)\end{array}$ \\
\hline $\begin{array}{l}\text { Argissolo Vermelho Amarelo Tb Distrófico câmbico } \\
\text { (PVA1) }\end{array}$ & $\begin{array}{l}\text { A moderado, textura argilosa, relevo forte ondulado, } \\
\text { substrato granito gnáissico, ocorrência na área de } \\
\text { pastagem, com declividade de } 35 \% \text {. Coordenadas } \\
\text { geográficas: } 22^{\circ} 52^{\prime} 52.56^{\prime} \mathrm{S} \text { e } 46^{\circ} 15^{\prime} 28.17^{\prime} \mathrm{O}(\mathrm{P} 3)\end{array}$ \\
\hline $\begin{array}{l}\text { Argissolo Vermelho Amarelo Tb Distrófico câmbico } \\
\text { (PVA2) }\end{array}$ & $\begin{array}{l}\text { A moderado, textura argilosa, relevo forte ondulado, } \\
\text { substrato granito gnáissico, ocorrência na área de } \\
\text { pastagem, com declividade de } 23 \% \text {. Coordenadas } \\
\text { geográficas: } 22^{\circ} 52^{\prime} 53.03^{\prime} \text { S e } 46^{\circ} 15^{\prime} 26.81^{\prime} \mathrm{O} \text { (P4) }\end{array}$ \\
\hline Neossolo Litólico Tb Distrófico (RL1) & $\begin{array}{l}\text { A moderado, textura argilosa, relevo forte ondulado, } \\
\text { substrato granito gnáissico, ocorrência na área de } \\
\text { pastagem, com declividade de } 21 \% \text {. Coordenadas } \\
\text { geográficas: } 22^{\circ} 52^{\prime} 53.39^{\prime} \text { S e } 46^{\circ} 15^{\prime} 25.12^{\prime \prime O} \text { (P5) }\end{array}$ \\
\hline Neossolo Litólico Tb Distrófico (RL2) & $\begin{array}{l}\text { A moderado, textura argilosa, relevo ondulado, } \\
\text { substrato granito gnáissico - ocorrência na área de } \\
\text { pastagem, com declividade de } 19 \% \text {. Coordenadas } \\
\text { geográficas: } 22^{\circ} 52^{\prime} 53.51^{\prime} \text { S e } 46^{\circ} 15^{\prime} 23.40^{\prime \prime O} \text { (P6) }\end{array}$ \\
\hline
\end{tabular}

Em laboratório foram realizadas análises de densidade do solo (Ds), condutividade hidráulica $(\mathrm{K})$, teor de argila e carbono orgânico (Corg), este convertido em MO, de acordo com o Manual de Métodos de Análise de Solos (DONAGEMA et al., 2011). Tais informações subsidiaram a discussão dos resultados das perdas de água e de sedimentos, de acordo com Gomes et al. (2017). A declividade foi obtida por nível óptico (LIMA et al., 2010).

\section{Esquema amostral}

O esquema de amostragem adotado foi em parcelas de $1 \mathrm{~m}^{2}$ (calhas tipo Gerlach), de acordo com Pinese et al. (2006), com três repetições (R1, R2 e R3) por ponto, considerando seis pontos (P1 a P6), sendo o P1 sob cobertura de mata nativa e os demais pontos (P2 a P6) sob cobertura de pastagem - Brachiaria decumbens $(\mathrm{Bd})$, com $15 \mathrm{~cm}$ de altura, obedecendo ao fatorial: 3 (repetições) $x 6$ (pontos de coleta $)=18$. A Figura 3 exemplifica a montagem das parcelas em cada ponto. 
Figura 3. Parcelas do ponto P2 com cobertura de pastagem. A amostragem iniciou-se somente após o recobrimento total da parcela com o capim.

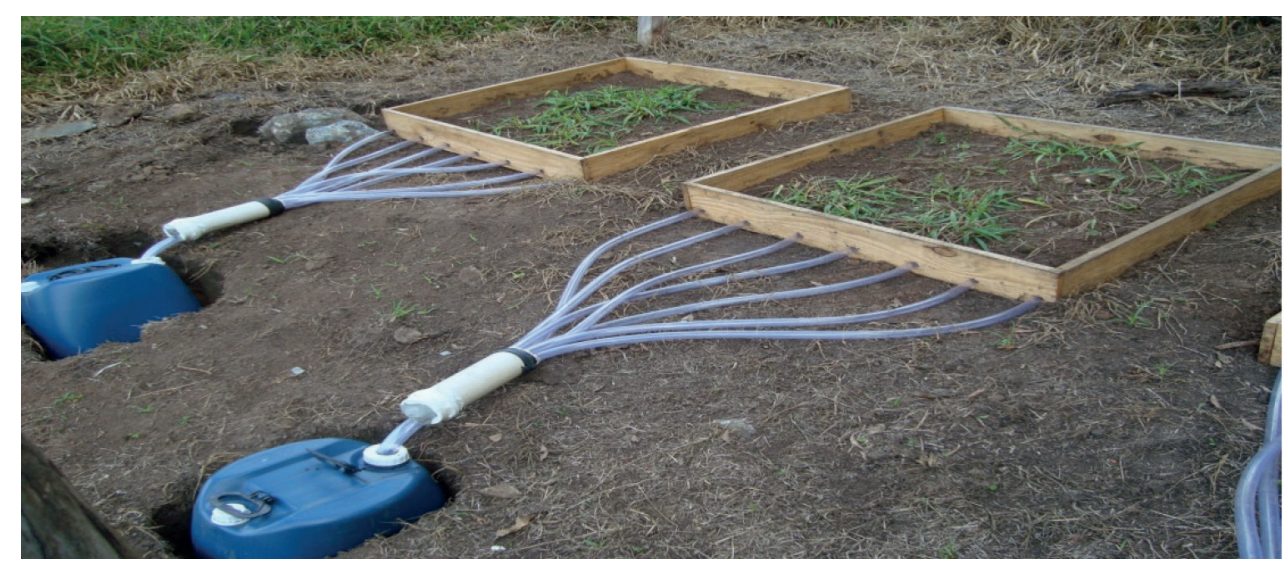

Fonte: Gomes et al., (2017).

\section{Coleta e quantificação das amostras de água e de sedimentos}

A coleta das amostras de água e de sedimentos estendeu-se por um período de 7 meses, com o início em 24/5/2016, com chuva acumulada desde o dia 10 do mesmo mês, e o término em $10 / 12 / 2016$, com chuva acumulada desde o dia 1\%12. O volume total de precipitação no período foi de $649,3 \mathrm{~mm}$. O armazenamento de água e de sedimento foi realizado por meio de bombonas (tambores plásticos) com capacidade máxima de 50 L (Figura 2), com três repetições (três parcelas de $1 \mathrm{~m} \mathrm{x} 1 \mathrm{~m}$ ) para cada tipo de solo (P1 a P6), totalizando 18 parcelas de coleta. As coletas levaram em conta os eventos de chuva, com amostragem realizada após cada evento igual ou superior a $5 \mathrm{~mm}$. Os volumes de água coletados foram quantificados em $\mathrm{mL} / \mathrm{m}^{2}$ e convertidos em $\mathrm{m}^{3} / \mathrm{ha}$; o sedimento foi quantificado em $\mathrm{g} / \mathrm{m}^{2}$ e convertido em $\mathrm{kg} / \mathrm{ha}$. Assim foi possível estimar as perdas de água e de sedimentos com a avaliação do total de água e de sedimentos armazenados nas bombonas (GOMES et al., 2017).

\section{Resultados e Discussão}

Os resultados dos parâmetros físicos selecionados, bem como os valores de perdas de água e de sedimentos, estão expressos na Tabela 2.

Tabela 2. Declividade (D) da topossequência e parâmetros de solo K, Ds, Teor de Argila e MO obtidos pela média entre as profundidades: $0 \mathrm{~cm}-20 \mathrm{~cm}$ e de $20 \mathrm{~cm}-40 \mathrm{~cm}$ e valores de perdas de água e sedimentos por hectare, considerando 649,3 $\mathrm{mm}$ de precipitação.

\begin{tabular}{|c|c|c|c|c|c|c|c|}
\hline Solo & $\begin{array}{c}\text { D } \\
(\%)\end{array}$ & $\underset{\left(\mathrm{cm} \cdot \mathrm{h}^{-1}\right)}{\mathrm{K}}$ & $\begin{array}{c}\text { Ds } \\
\left(\mathrm{g} \cdot \mathrm{cm}^{-3}\right)\end{array}$ & $\begin{array}{l}\text { Argila } \\
\left(\mathrm{g} \mathrm{kg}^{-1}\right)\end{array}$ & $\begin{array}{c}\text { MO } \\
\left(\mathrm{g}^{\mathrm{kg}} \mathrm{kg}^{-1}\right)\end{array}$ & $\begin{array}{c}\text { Perdas } \\
\text { Água } \\
\left(\mathrm{m}^{3} \cdot \mathbf{h a}^{-1}\right)\end{array}$ & $\begin{array}{c}\text { Perdas } \\
\text { Sedimento } \\
\left(\mathrm{kg}^{\left.-h a^{-1}\right)}\right.\end{array}$ \\
\hline $\mathrm{CHe}$ & 55 & 3,39 & 1,1 & 560 & 158,07 & 380,09 & 4,71 \\
\hline $\mathrm{CHd}$ & 53 & 3,25 & 1,2 & 550 & 147,04 & 392,49 & 7,10 \\
\hline PVA1 & 35 & 1,51 & 1,5 & 540 & 118,38 & 437,25 & 14,42 \\
\hline PVA2 & 23 & 1,85 & 1,4 & 510 & 105,26 & 509,95 & 14,96 \\
\hline RL1 & 21 & 0,96 & 1,6 & 480 & 109,83 & 948,03 & 20,19 \\
\hline RL2 & 19 & 0,85 & 1,8 & 470 & 96,40 & 901,22 & 23,31 \\
\hline
\end{tabular}

Fonte: Adaptado de Gomes et al. (2017). 


\section{Perdas de água e de sedimentos sob as coberturas de mata e de pastagem}

A avaliação das perdas de água e de sedimentos por escoamento superficial em função da cobertura vegetal (Tabela 2) mostra que sob a mata (solo CHe) essas perdas são muito inferiores quando comparadas com a cobertura de pastagem (solos PVA1, PVA2, RL1 e RL2). A exceção é o solo $\mathrm{CHd}$, que apresenta pouca diferença em relação ao $\mathrm{CHe}$, particularmente em relação às perdas de água, cujos valores correspondem a $392,49 \mathrm{~m}^{3} \cdot \mathrm{ha}^{-1}$ e $380,09 \mathrm{~m}^{3} \cdot \mathrm{ha}^{-1}$. Para os sedimentos, os valores de perdas apresentam diferenças maiores, com 4,71 kg.ha-1 para o $\mathrm{CHe}$ e 7,10 kg.ha-1 ${ }^{-1}$ para o CHd. Aqui fica evidente a ação protetora da mata em relação ao transporte de sedimentos, já que os solos são semelhantes.

No entanto, quando se avaliam as perdas de diferentes solos sob a mesma cobertura, caso da pastagem, fica evidente que as propriedades do solo são muito mais relevantes no processo de perdas. A densidade do solo (Ds), por exemplo, exerce função essencial na taxa de infiltração do solo, cuja resposta é atendida de imediato pela condutividade hidráulica (K).

\section{Perdas de água e de sedimentos sob os diferentes tipos de solo}

Quando se comparam os diversos tipos de solo (Tabela 2), as perdas de água e de sedimentos refletem as particularidades de cada um deles. Os diferentes valores de declividade $(\mathrm{D} \%)$, condutividade hidráulica (K), densidade do solo (Ds), matéria orgânica (MO) e teor de argila, por exemplo, exercem influência nos processos de perda.

Isso pode ser comprovado quando se faz uma comparação entre os solos CHd e RL2, por exemplo, que estão sob a cobertura de pastagem. Os valores de perdas são muito distintos, tanto de água quanto de sedimentos. Enquanto no CHd a perda de água é de 392,49 $\mathrm{m}^{3}$.ha-1 , no RL2 esse valor é de $901,22 \mathrm{~m}^{3} \cdot \mathrm{ha}^{-1}$. Para os sedimentos, os valores de perdas são de $7,10 \mathrm{~kg} \cdot \mathrm{ha}^{-1}$ no CHd e de 23,31 kg.hat ${ }^{-1}$ no RL2.

Como já considerado no item anterior, fica evidente que a mesma cobertura vegetal exerce pouca influência sobre as perdas, em comparação com os parâmetros físicos de diferentes tipos de solo. Na prática isso significa que diferentes solos sob a mesma cobertura vegetal apresentam valores distintos de perdas de água e de sedimentos.

Por isso mesmo é importante que o proprietário rural conheça algumas características dos solos da sua propriedade. A partir desse conhecimento é possível fazer uma divisão da área e estabelecer os diferentes usos de acordo com a capacidade de uso do solo (PEREIRA; TOSTO, 2012), o que vai contribuir para a sustentabilidade da propriedade, tornando-a mais produtiva e ambientalmente mais equilibrada.

\section{Relação entre as perdas totais de água e de sedimentos e os serviços ambientais}

Os serviços ambientais são realizados na propriedade rural no sentido de viabilizá-la, tanto do ponto de vista econômico quanto ambiental. Assim, no caso da sub-bacia do Ribeirão das Posses, cuja área total é em torno de 1.200 ha, foi realizada uma projeção de perdas, considerando as informações da Tabela 2, em que os solos representam $60 \%$ do total existente na sub-bacia 
(LIMA et al., 2013b). Tal projeção remete aos valores anuais mostrados, com precipitação de $1.477 \mathrm{~mm} \mathrm{ano}^{-1}$ (SILVA et al., 2013), de acordo com a Tabela 3.

A Tabela 3 mostra uma projeção de perdas de água e de sedimentos para toda a área da sub-bacia do Ribeirão das Posses, com os valores de $1.588,38 \mathrm{~m}^{3} / \mathrm{ha} / \mathrm{ano}$ e $39,82 \mathrm{~kg} / \mathrm{ha} / \mathrm{ano}$, considerando as três classes (CH, PVA e RL) de solos avaliadas que correspondem a $60 \%$ do total da área (720 ha).

Tabela 3.Valores de perdas de água e sedimentos por hectare projetados para 1 ano $(1.477 \mathrm{~mm})$ na sub-bacia do Ribeirão das Posses, Extrema, MG, considerando a ocorrência de 60\% dos solos.

\begin{tabular}{|cccc|}
\hline \multirow{2}{*}{ Solo } & Ocorrência na sub-bacia & & \\
\cline { 3 - 4 } & $(\%)$ & 864,61 & \\
CHe & \multirow{2}{*}{41} & 892,82 & 10,71 \\
CHd & & 994,63 & 16,15 \\
PVA1 & 10 & $1.160,01$ & 36,48 \\
PVA2 & & $2.156,53$ & 34,03 \\
RL1 & 9 & $2.050,05$ & 45,92 \\
RL2 & - & $\mathbf{1 . 5 8 8 , 3 8}$ & 53,02 \\
Média ponderada & & & $\mathbf{3 9 , 8 2}$ \\
\hline
\end{tabular}

Fonte: Adaptado de Gomes et al. (2017).

Se toda a sub-bacia do Ribeirão das Posses fosse constituída pelas três classes de solo citadas, as perdas seriam de $1.906,05 \mathrm{~m}^{3} / \mathrm{ha} /$ ano e de $47,84 \mathrm{~kg} / \mathrm{ha} /$ ano para água e sedimentos respectivamente.

Frente a esse cenário de perdas, ainda que estimado para $60 \%$ das classes de solo existentes na sub-bacia, se o solo for bem manejado por meio dos serviços ambientais, pode atuar naturalmente na provisão dos serviços ecossistêmicos como "reservatório e filtro de água" para que assim ocorra a absorção e o armazenamento de água e de nutrientes, permitindo o desenvolvimento vegetal, o controle da erosão, do assoreamento e das enchentes.

Nesse sentido, os serviços ambientais necessários para minimizar as perdas de água e de sedimentos na sub-bacia do Ribeirão das Posses devem contemplar práticas de manejo e conservação do solo, com destaque para as de ordem mecânica (curvas de nível e terraços) e vegetativa (cordões em nível) nas áreas localizadas entre os interflúvios, onde ocorrem as atividades agropecuárias. Nesses locais os serviços ambientais promoverão o recarregamento do lençol freático, permitindo certa uniformidade na vazão do Ribeirão das Posses durante todo o ano.

A recomposição da vegetação natural em áreas de nascentes e margens dos cursos d'água bem como o impedimento do acesso de animais a essas áreas constituem serviços ambientais que contribuirão para o aumento do volume de água dos mananciais desde a nascente.

É importante ressaltar que o cenário de perdas projetado, de acordo com a Tabela 3, considera que $60 \%$ dos solos da sub-bacia estão cobertos com vegetação, seja mata ou pastagem, na proporção de $10 \%$ e $90 \%$, respectivamente, e que, no caso dessa última, o porte ou altura é de 
cerca de $15 \mathrm{~cm}$, o que, em essência, traduz somente parte da realidade da sub-bacia. Esse cenário projetado explica, por exemplo, os valores bem mais reduzidos em relação àqueles de perdas de solo em culturas anuais, em que quase sempre a cobertura vegetal é menos densa, com exposição parcial do solo. De fato, esses resultados têm por premissa contribuir para estudos mais específicos em relação a perdas de solo, quando então devem ser usadas equações pertinentes como, por exemplo, a USLE/RUSLE.

Os ganhos com a implantação dos serviços ambientais estão relacionados diretamente com a redução substancial das perdas de água e de sedimentos.

Nesse sentido podem ser feitos os seguintes questionamentos: quanto custa $1.143 .633 \mathrm{~m}^{3}$ de água/ano e $28.670 \mathrm{~kg}$ de sedimentos/ano (solos)? No caso da água, considerando o custo médio do metro cúbico de $\mathrm{R} \$ 3,00$ ao consumidor (SAAD, 2016) e o valor citado de $1.143 .633 \mathrm{~m}^{3}$, tem-se a quantia correspondente a $\mathrm{R} \$ 3.430 .899,00 /$ ano, o que representa um valor considerável frente às 53 propriedades rurais existentes na sub-bacia do Ribeirão das Posses. No caso das perdas de sedimentos, ainda que subestimadas, o valor pode ser calculado em relação à fertilidade, que corresponde a US\$18,15 (R\$ 70,78) ha-1 ano-1 (DECHEN et al., 2015), aplicado a uma área com $90 \%$ de cobertura vegetal. Nesse caso, não se considera a perda em relação ao peso do solo (t/ha), mas o que ela representa em termos de gastos para reposição dos nutrientes perdidos por escoamento superficial. A sub-bacia do Ribeirão das Posses possui $99 \%$ de sua área com cobertura vegetal, sendo 1\% ocupada com estradas (SILVA et al., 2013). Considerando que sua área total é de 1.200 ha, tem-se então como valor de perdas de fertilidade algo da ordem de US\$21.780, o que corresponde a um valor em torno de $\mathrm{R} \$ 85.000,00$. Esse valor tem por base o preço médio do dólar no segundo semestre de $2019^{7}$.

Diante do exposto fica evidente que as perdas de água e de sedimentos implicam, de fato, em problemas para a propriedade, como a diminuição da fertilidade do solo, a diminuição na oferta de água e, consequentemente, a queda no rendimento das atividades agrícolas.

No caso de Extrema, MG, o Projeto Conservador das Águas contempla o pagamento por serviços ambientais (PSA), com um valor estabelecido por hectare, independentemente se parte da propriedade está ou não degradada. Os proprietários recebem 100 Unidades Fiscais de Extrema (Ufex), o que equivale a R\$235,00 por hectare, valor esse referente ao ano de 2015 (SAAD, 2016). Os serviços ambientais contemplados no Programa Produtor de Água incluem a recomposição da vegetação nativa nas áreas de mais alta declividade, nas áreas de nascentes e nas margens dos cursos d'água. Nesse processo é realizado o isolamento dos animais para que não tenham acesso aos cursos d'água, evitando assim a formação de sulcos e erosões junto às margens. No escopo do programa estão inseridos também convênios com instituições de pesquisa e de ensino, com uma base de apoio logístico e de troca de experiências (centro de estudos) localizada nas imediações da nascente principal do Ribeirão das Posses.

$\$ 1,00=\mathrm{R} \$ 3,90$ 


\section{Considerações Finais}

Os serviços ambientais constituem ações indispensáveis em áreas de alta vulnerabilidade a eventos de perdas de água e solos por escoamento superficial, escassez hídrica e de enchentes, como é o caso da sub-bacia do Ribeirão das Posses.

Os serviços ambientais necessários para controlar as perdas de água e de sedimentos na sub-bacia do Ribeirão das Posses devem contemplar práticas de manejo e conservação do solo, com destaque para as de ordem mecânica (curvas de nível e terraços) e vegetativa (cordões em nível) nas áreas localizadas entre os interflúvios, onde ocorrem as atividades agropecuárias.

Os resultados esperados com a adoção dos serviços ambientais incluem o recarregamento regular do lençol freático, com redução considerável da taxa de sedimentos em suspensão, bem como a predominância de uma vazão mais uniforme do Ribeirão das Posses durante todo o ano.

\section{Referências}

AGÊnCia NACIONAl das ÁGUAS - ANA. Programa Produtor de Água. Brasília, DF, 2008. 22 p. Disponível em: http://produtordeagua.ana.gov.br/Portals/0/DocsDNN6/documentos/Folder\%2020Programa\%20Produtor\%20de\%20\%C3\%81gua.pdf. Acesso em: 23 set. 2016.

BRANCO, C. S. Análise exploratória de parâmetros de qualidade dos biossistemas das nascentes da Sub bacia de Posses em Extrema/MG. 2018. 119 p. Tese (Doutorado) - Universidade de São Paulo, Escola Superior de Agricultura "Luiz de Queiroz", Piracicaba.

DECHEN, S. C. F.; TELLES, T. S.; GUIMARÃES, M. F.; DE MARIA, I. C. Perdas e custos associados à erosão hídrica em função de taxas de cobertura do solo. Bragantia, Campinas, v. 74, n. 2, p. 224-233, 2015.

DONAGEMA, G. K.; CAMPOS, D. V. B. de; CALDERANO, S. B.; TEIXEIRA, W. G.; VIANA, J. H. M. (Org.). Manual de métodos de análise de solo. 2. ed. rev. Rio de Janeiro: Embrapa Solos, 2011. 230 p. (Embrapa Solos. Documentos, 132).

FREITAS, D. A. F.; SILVA, M. L. N.; CARDOSO, E. L.; CURI, N. Índices de qualidade do solo sob diferentes sistemas de uso e manejo florestal e cerrado nativo adjacente. Revista de Ciência Agronômica, v. 43, n. 3, p. 417-428, 2012.

GOMES, M. A. F.; PEREIRA, L. C.; FIGUEIREDO, R. de O.; TÔSTO, S. G. Perdas de água e de sedimentos em uma topossequência sob as coberturas de pastagem e de mata nativa na sub-bacia do Ribeirão das Posses, município de Extrema, MG. Campinas: Embrapa Monitoramento por Satélite, 2017. 12 p. (Embrapa Monitoramento por Satélite. Comunicado Técnico, 41).

LIMA, G. C.; SILVA, M. L. N.; CURI, N.; SILVA, M. A.; OLIVEIRA, A. H.; AVANZI, J. C.; UMMUS, M. E. Avaliação da cobertura vegetal pelo índice de vegetação por diferença normalizada (IVDN). AmbiAgua, Taubaté, v. 8, n. 2, p. 204-214, 2013 a.

LIMA, G. C.; SILVA, M. L. N.; CURI, N.; SILVA, M. A. da; OLIVEIRA, A. H.; AVANZI, J. C.; FREITAS, D. A. F. Estimativa do potencial de recarga na sub-bacia das Posses, Extrema (MG), em função dos atributos fisiográficos, pedológicos e topográficos. Geociências, v. 32, n. 1, p. 51-62, 2013 b.

LIMA, J. M.; OLIVEIRA, G. C.; MELO, C. R. Conservação do solo e da água. Notas de aulas práticas. Lavras: UFLA, 2010. 62 p. (Disciplina GCS 104). 
MILLENNIUN ECOSYSTEM ASSESMENT. Ecosystems and human well-being; global assessment reports. Washington, DC: Island Press, 2005.

OLIVEIRA, A. H.; SILVA, M. A.; SILVA, M. L. N.; AVANZI, J. C.; CURI, N.; LIMA, G. C. Caracterização ambiental e predição dos teores de matéria orgânica do solo na sub-Bacia do Salto, Extrema, MG. Semina: Ciências Agrárias, v. 33, n. 1, p.147-160, 2012.

PEREIRA, L. C.; TOSTO, S. G. Capacidade de uso das terras como base para a avaliação do desenvolvimento rural sustentável In: SEMINÁRIO INTERNACIONAL NOVA TERRITORIALIDADES E DESENVOLVIMENTO SUSTENTÁVEL, 2., 2012, Recife. Anais... Recife: GRAPP, 2012. 9 p.

PINESE, J. F. J.; GARBIN, E. J.; RODRIGUES, S. C. Análise do transporte de sedimentos com diferentes tipos de uso do solo em calhas de Gerlach (1966) na Fazenda Experimental do Glória, Uberlândia -- MG. In: SIMPÓSIO NACIONAL DE GEOMORFOLOGIA, 6., 2006, Goiânia. Geomorfologia tropical e subtropical: processos, métodos e técnicas: anais/resumos. Goiânia: IAG: UCG, 2006. 9 p.

PONTES, L. M.; BISPO, D. F.; SILVA, M. L. N.; BATISTA, P. V. G.; CÂNDIDO, B. M.; SILVA, T. P. Monitoramento da erosão hídrica na sub-bacia das Posses, Extrema, MG, Brasil. In: CONGRESO LATINOAMERCIANO DE LA CIÊNCIA DEL SUELO; CONGRESO PERUANO DE LA CIENCIA DEL SUELO, 16., 2014, Cusco. Educar para preservar el suelo y conservar la vida en la tierra. Cusco: Centro de Convenciones de la Municipalidad del Cusco, 2014. p. 2-7.

SAAD, S. I. Modelagem e valoração dos serviços ambientais hidrológicos da recuperação da vegetação no Ribeirão das Posses, Extrema, MG. 2016. 169 p. Tese (Doutorado em Ciências Ambientais) - Universidade de São Paulo, São Paulo.

SANTOS, H. G. dos; JACOMINE, P. K. T.; ANJOS, L. H. C. dos; OLIVEIRA, V. A. de; LUMBRERAS, J. F.; COELHO, M. R.; ALMEIDA, J. A. de; ARAUJO FILHO, J. C. de; OLIVEIRA, J. B. de; CUNHA, T. J. F. Sistema Brasileiro de Classificação de Solos. 5. ed. rev. e ampl. Brasília, DF: Embrapa, 2018. E-book.

SILVA, M. A.; FREITAS, D. A. F. de; SILVA, M. L. N.; OLIVEIRA, A. H.; LIMA, G. C. L.; CURI, N. Sistema de informações geográficas no planejamento de uso do solo. Revista Brasileira de Ciências Agrárias, Recife, v. 8, n. 2, p. 316-323, 2013. 